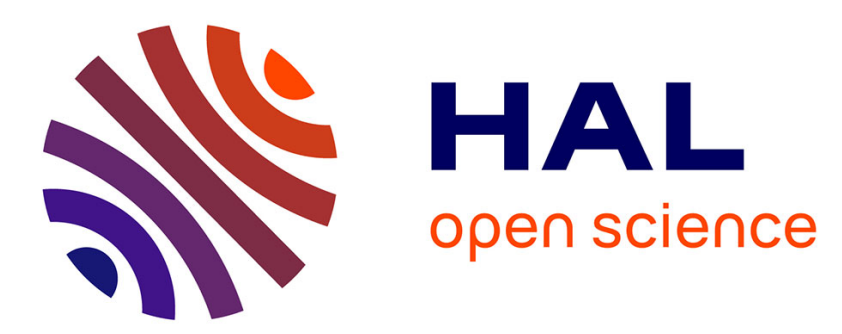

\title{
Single-strand DNA translation initiation step analyzed by Isothermal Titration Calorimetry.
}

\author{
Luminita Damian, Claire Marty-Detraves, Mathias Winterhalter, Didier \\ Fournier, Laurent Paquereau
}

\section{- To cite this version:}

Luminita Damian, Claire Marty-Detraves, Mathias Winterhalter, Didier Fournier, Laurent Paquereau. Single-strand DNA translation initiation step analyzed by Isothermal Titration Calorimetry.. Biochemical and Biophysical Research Communications, 2009, 385 (3), pp.296-301. 10.1016/j.bbrc.2009.05.044 . hal-00691363

\section{HAL Id: hal-00691363 https://hal.science/hal-00691363}

Submitted on 27 Apr 2012

HAL is a multi-disciplinary open access archive for the deposit and dissemination of scientific research documents, whether they are published or not. The documents may come from teaching and research institutions in France or abroad, or from public or private research centers.
L'archive ouverte pluridisciplinaire HAL, est destinée au dépôt et à la diffusion de documents scientifiques de niveau recherche, publiés ou non, émanant des établissements d'enseignement et de recherche français ou étrangers, des laboratoires publics ou privés. 


\section{Single strand DNA translation initiation step analyzed by Isothermal Titration Calorimetry.}

Luminita Damian ${ }^{1,2,3}$, Claire Marty-Detraves ${ }^{1,2}$, Mathias Winterhalter $^{3}$, Didier Fournier $^{1,2}$, Laurent Paquereau ${ }^{1,2 \S}$.

${ }^{1}$ CNRS; IPBS (Institut de Pharmacologie et de Biologie Structurale); 205

route de Narbonne, F-31077 Toulouse, France

${ }^{2}$ Université de Toulouse; UPS; IPBS; F-31077 Toulouse, France

${ }^{3}$ IUB, School of Engineering and Science, D-28727 Bremen, Germany

${ }^{\S}$ Corresponding author: Laurent.Paquereau@ipbs.fr

Tél : +33 (0)561 175859

Fax : +33(0)561 175994

Email addresses:

LD: 1uminitadamian@microcal.eu.com

CMD: claire.detraves@free.fr

DF: Didier.Fournier@ipbs.fr

LP: Laurent.Paquereau@,ipbs.fr 


\begin{abstract}
Is single-strand DNA translatable? Since the 60's, the question still remains whether or not DNA could be directly translated into protein. Some discrepancies in the results were reported about functional translation of single-strand DNA but all results converged on a similar behavior of RNA and ssDNA in the initiation step. Isothermal Titration Calorimetry method was used to determine thermodynamic constants of interaction between single-strand DNA and S30 extract of E. Coli. Our results showed that the binding was not affected by the nature of the template tested and the dissociation constants were in the same range when ssDNA $\left(\mathrm{Kd}=3.62 \pm 2.110^{-8} \mathrm{M}\right)$ or the RNA corresponding sequence $\left(\mathrm{Kd}=2.7 \pm 0.8210^{-8} \mathrm{M}\right)$ bearing SD/ATG sequences were used. The binding specificity was confirmed by antibiotic interferences which block the initiation complex formation. These results suggest that the limiting step in translation of ssDNA is the elongation process.
\end{abstract}

Keywords: DNA translation: Isothermal Titration Calorimetry: 


\section{Introduction}

Since the discovery of the genetic code [1] and of messenger RNA (for review see [2]), the molecular biology dogma is an evident pathway for the expression from gene to protein. Nevertheless, as early as 1964, DNA was used in vitro to study translation and the question still remains whether or not DNA could be directly translated into protein. The first published works tried to determine whether single-stranded DNA (ssDNA) might be able to directly program the synthesis of proteins $[3,4]$. Single-stranded DNA and circular messenger DNA were then used in direct translation systems for different purposes: to check the fidelity of the direct translation [5], to demonstrate that ribosomes do not require a free end on a messenger to initiate protein synthesis [6], to show that binding of fmet-tRNA and ssDNA to the ribosome could occur without neomycin which is necessary for elongation with these matrix [7], to test a synthetic ssDNA as ribosome binding site [8], and finally, to make comparisons between RNA and ssDNA in their ability to program ribosomes for initiation and termination of translation [9]. In all papers cited above, all results converge towards a similar behavior of RNA and ssDNA in the initiation step, in spite of some discrepancy concerning the elongation step of translation.

The formation of the initiation complex involves many partners which are largely described in the literature but the results are sometimes contradictory. For instance, the absence of initiation factors, especially IF3, does not significantly affect the interaction of the $30 \mathrm{~S}$ subunits of ribosome and mRNA [10], although its role in promoting mRNA binding on ribosomes was demonstrated elsewhere [11]. On the other hand, the Shine-Dalgarno (SD) sequence [12], which is localized inside the Ribosome Binding Site (RBS), is clearly involved in the interaction between mRNA and the $30 \mathrm{~S}$ ribosome subunit. Therefore, this sequence is an unambiguous signal to test the specificity of these interactions. 
In this biological process, the secondary or tertiary structures of mRNA play a crucial role for the control of the translation initiation [13-15]. We choose to exclude this aspect because i) RNA and ssDNA do not shares the same secondary structures [16] ii) The structural organization of both RNA and ssDNA is difficult to predict and control in a biological context, even if fine structural results have pointed up the interactions between mRNA and 30S subunits $[17,18]$.

In this context, we tried to establish the thermodynamic values of this interaction in a global way, in order to determine and to compare with a sensitive method the binding constants for these two templates (mRNA and ssDNA). Some studies have reported association constant in particularly for interactions between the Shine-Dalgarno sequence on mRNA and ribosomes, with a value near $2 \times 10^{7} \mathrm{M}^{-1}[10]$. This range of affinity corresponds to the sensibility of the Isothermal titration calorimetry method, which allows us to access not only the binding constants but also the thermodynamic values of these interactions.

\section{Materials and methods}

\section{S30 extracts}

E. coli S30 extracts were prepared accordingly to Zubay [19], with some minor modifications introduced by Pratt [20]. The S30 extract was quantified by measuring the optical density at $260 \mathrm{~nm} . \mathrm{DO}_{260 \mathrm{~nm}}$ of 1480 corresponds to $100 \mathrm{mg} / \mathrm{ml}$ of ribosomic extract. The concentration of $\mathrm{S} 30$ extracts stored at $-70^{\circ} \mathrm{C}$ was $1.3 \mathrm{mg} / \mathrm{ml}$.

\section{Oligonucleotides}

All oligonucleotides were purchased from Eurobio (Table 1).

\section{In vitro translation and detection of peptide synthesis}


E. coli S30 Extract System for Linear Templates purchased from Promega was used in translation assays. Oligonucleotides were tested between 10 to $500 \mu \mathrm{g}$ and for several incubation times ( $2 \mathrm{~h}$ to overnight).

Mouse monoclonal antibody (purchase from Oncogene ${ }^{\mathrm{TM}}$ ) against c-myc epitope (EQKLISEEDL) was used in dot-blot experiments. C-myc synthetic peptide (MASMQKLISEEDL) was used as positive control. Primary antibody was detected and revealed with anti-mouse IgG peroxidase-linked whole antibody from sheep (Amersham Biosciences). To enhance the sensitivity of detection, c-myc epitope was produced with a 6 Histidine tag allowing purification on Dynabeads ${ }^{\circledR} \mathrm{TALON}^{\mathrm{TM}}$ (Invitrogen). Fusion peptide (6(His)/c-myc) was separated of translation mix by affinity with cobalt binds on Dynabeads. Mouse monoclonal primary antibody against c-myc epitope was detected with anti-mouse secondary antibody from rabbit. To amplify the signal a third anti-rabbit antibody FITC-linked from sheep was used $(\lambda \operatorname{exc}=490 \mathrm{~nm} ; \lambda$ em $=520 \mathrm{~nm})$.

\section{In vitro transcription}

Synthetic RNA was obtained by T7 RNA Run off transcription of a double strand DNA containing T7 promoter [21]. Oligonucleotides T7/SD/ATG and AntiT7/SD/ATG were hybridized in Ulh buffer (40mM TrisHCl pH 8, 0.01\% Triton X100, 1mM Spermidine) and $100 \mathrm{mM} \mathrm{NaCl}$ by heating $3 \mathrm{~min}$ at $95^{\circ} \mathrm{C}$ and cooling slowly until room temperature. Run off transcription were achieved in Ulh buffer, with $1 \mu \mathrm{M}$ of double strand oligonucleotide, $5 \mathrm{mM}$ DTT, $5 \mathrm{mM}$ of each NTP, $38 \mathrm{mM} \mathrm{MgCl}_{2}$ and 2 units of T7 RNA polymerase (NEB) at $37^{\circ} \mathrm{C}$ ON. The reaction mixture was treated by 10 units of DNaseI for $1 \mathrm{~h}$ at $37^{\circ} \mathrm{C}$ and phenol extracted at $\mathrm{pH}$ 4. RNA was precipitated in ethanol, resuspended in $\mathrm{H}_{2} \mathrm{O}$ and quantified at 260nm. All solutions except Spermidine and Tris-HCl were DEPC treated and autoclaved. 


\section{Isothermal Titration Calorimetry, ITC}

Isothermal titration calorimetry was performed using a VP-ITC microcalorimeter from Microcal Inc. (Northampton, MA). Several experiments were performed to determine the binding constant values. Injections of 2 to $10 \mu \mathrm{l}$ of oligonucleotide were added by computercontrolled $296 \mu$ microsyringe at intervals of 200 to 300 seconds into the S30 extract (cell volume $=1.437 \mathrm{ml})$. The experiments were performed at $30^{\circ} \mathrm{C}\left(303^{\circ} \mathrm{K}\right)$, with a stirring speed of $300 \mathrm{rpm}$. The S30 extract concentration varied between $0.17-0.43 \mu \mathrm{M}$ and the oligonucleotides concentrations between 5-10 $\mu \mathrm{M}$ except for the binding of anti-SD $(25 \mu \mathrm{M})$ with SD/ATG oligonucleotide $(250 \mu \mathrm{M})$. S30 buffer was used to resuspend and dilute oligonucleotides. For RNA, the S30 buffer was previously treated with DEPC. Interaction of SD and AntiSD oligonucleotides was performed in $50 \mathrm{mM} \mathrm{Na} 2 \mathrm{HPO}_{4} / \mathrm{NaH}_{2} \mathrm{PO}_{4} \mathrm{pH} 8,100$ $\mathrm{mM} \mathrm{NaCl}$ at $25^{\circ} \mathrm{C}$. All solutions were degassed before use. Antibiotics were added to the $\mathrm{S} 30$ extract and to the oligonucleotide solution before measurements. Several blind titrations were performed to determine and correct for non-specific heat contributions (heat of dilution). The experimental data were fitted to a theoretical titration curve, using software supplied by Microcal, with $\Delta \mathrm{H}$ (enthalpy change in $\mathrm{kcal} /$ mole), $\mathrm{K}_{\mathrm{a}}$ (association constant in $\mathrm{M}^{-1}$ ) and $\mathrm{n}$ (number of binding sites), as adjustable parameters. The instrument was calibrated using the built-in mode of electric field heat pulses. Thermodynamic parameters were calculated from the relation:

$$
\Delta G=\Delta H-T \Delta S=-R T \ln K_{a}
$$

where the $\Delta \mathrm{G}, \Delta \mathrm{H}$ and $\Delta \mathrm{S}$ represent the changes in free energy, enthalpy and entropy of binding; $\mathrm{T}$ is the absolute temperature and $\mathrm{R}=1.98 \mathrm{cal} \mathrm{mol}^{-1} \mathrm{~K}^{-1}$.

\section{Results}




\section{Design of oligonucleotides}

Oligonucleotides were designed to avoid any secondary structures in accessing the binding constants between S30 extract and specific signal sequences. The Shine-Dalgarno sequence, for example, is clearly involved in the translational efficiency, whether or not it is localized in a structured region [22]. Since protein/nucleic acid interactions were mostly observed with purine [23], we chose a polyT as framework for all the oligonucleotides to reduce nonspecific interactions with S30 extracts. The two main sequence signals involved in the initiation of translation were incorporated into the oligonucleotides. First, the SD sequence, which is complementary to the 3' terminal sequence of E.coli 16 S ribosomal RNA $[12,24]$, and second, the codon AUG, which is the most common initiator codon [25]. When these two sequences were present simultaneously, a distance of 9 nucleotides was introduced between them $[25,26]$. Oligonucleotides used in functional translation assays were designed with the same characteristics upstream the start codon but in order to use a fluorescent sensitive method to detect the corresponding peptide, SD/ATG/c-myc oligonucleotide as well as $\mathrm{SD} / \mathrm{ATG} / \mathrm{His}$ tag/c-myc, coding for c-myc epitope, were used to produce a covalent ${ }^{\mathrm{L}} \mathrm{tRNA} / \mathrm{c}-$ myc complex, which was more efficiently spotted on dot blot experiments. A $\mathrm{SD} / \mathrm{ATG} / \mathrm{Histag} / \mathrm{c}-\mathrm{myc} / \mathrm{Stop}$ oligonucleotide was designed to verify that ${ }^{\mathrm{L}} \mathrm{RNA}$ did not interfere with anti c-myc primary antibodies.

\section{Translation of single strand DNA}

In attempting to realize a functional assay, we tested the translation of different singlestranded DNA oligonucleotides in E. coli S30 extract. The SD/ATG/c-myc oligonucleotide led us to detect the peptide with a specific antibody directed against the c-myc epitope coupled to a second fluorescent antibody. The c-myc peptide was not detected, even if a third antibody was used to amplify the signal. The same negative results were obtained with an 
oligonucleotide bearing a Histidin-tag which allows a strong purification of potentially translated peptides. These two oligonucleotides did not contain a stop codon. Therefore, a peptidyl-tRNA complex should be formed and the release of the translated peptide should be blocked. We then tested this hypothesis with an oligonucleotide (SD/ATG/His tag/cmyc/Stop) which bore a stop codon, but none of these methods allowed us to show that an efficient translation of the single-stranded DNA oligonucleotides had occurred. Thus, it is obvious that the elongation process required for protein synthesis is not efficient with these matrixes.

\section{Binding of ribosome on single strand DNA}

Basal binding on nonspecific sequences were tested with a polydT oligonucleotide (Table 2). The dissociation constant $\left(\mathrm{Kd}=1.1610^{-7} \mathrm{M}\right)$ shows that the $\mathrm{S} 30$ extract shares an important affinity with this sequence, as it probably does with any random nucleotide sequence. The introduction of an ATG in the PolyT framework oligonucleotide (Oligo ATG) did not significantly change the thermodynamic values $\left(\mathrm{Kd}=1.3410^{-7} \mathrm{M}\right)$ and the start codon alone did not seem to be significantly involved in this binding. On the other hand, the presence of SD (Oligo SD) alone on ssDNA gave a dissociation constant of $4.110^{-8} \mathrm{M}$. (Table 2) which corresponds to a three-fold increase in affinity. The same three-fold increase in affinity was obtained when we compared ATG alone (Oligo ATG) or ATG in association with SD (Oligo $\mathrm{SD} / \mathrm{ATG}$ )(Figure 1 and Table 2), showing dissociation constants of $\mathrm{Kd}=1.3410^{-7} \mathrm{M}$ and $\mathrm{Kd}=$ 3.6 $10^{-8} \mathrm{M}$, respectively. The introduction of a known specific signal, such as $\mathrm{SD}$, in a polyT framework leads to an increase of the affinity constant. Then we checked if this increase was mainly due to the formation of the initiation complex as expected, or directly to the nucleic acid interactions. 
We tested the direct contribution of nucleic acids hybridization in this binding by incubating SD/ATG oligonucleotides with AntiSD oligonucleotides and we found a dissociation constant of $2.4 \pm 0.310^{-6} \mathrm{M}$. This corresponds to an affinity of two orders of magnitude lower than was observed with S30 extract (Figure 2 and Additional file 1). The involvement of ribonucleoprotein in this interaction was largely proven and these results are consistent with the theory of translation initiation.

\section{Interaction with RNA versus DNA}

RNA synthesized in vitro was used in control experiments. We used a full double strand DNA containing SD and ATG signals as template. After run off transcription, RNA was treated with DNAse I and extracted with acid phenol to eliminate any trace of DNA template. It was then quantified before the ITC experiments that were done in triplicate (Figure 3 and Additional file 2). The binding constants were compared to the values obtained from the corresponding ssDNA oligo SD/ATG (Table 3). Whatever the template, ssDNA or RNA, the affinity constant as well as the thermodynamic values were very similar and the ribosome binding site was recognized in the same way.

\section{Antibiotic interference on binding}

Several antibiotics act on the translation initiation step and were used to analyze the binding specificity of our system. In all experiments, antibiotics were added to both solutions, SD/ATG oligonucleotide and S30 extract, in order to avoid any dilution effect.

Aurintricarboxylic acid (ATA) prevents the attachment of mRNA to the 30S ribosome subunit [27]. An inhibition of interaction was observed for $1 \mu \mathrm{M}$ of ATA and the binding disappeared at $10 \mu \mathrm{M}$ (Figure $4 \mathrm{~A}) . \Delta \mathrm{H}$ values measured with $(-700 \mathrm{kcal} / \mathrm{mole})$ or without ATA $(-913$ 
$\mathrm{kcal} / \mathrm{mole}$ ) were similar while the molar ratio did not differ. These results correspond to the competitive behaviour of ATA which bound to the same site as SD/ATG oligonucleotides. Tetracycline, which blocked the binding of tRNA on the 30S subunit [28], shared the same global effect than ATA but at a higher concentration, since total inhibition was obtained for tetracycline concentrations between 100 and $250 \mu \mathrm{M}$ (Figure 4B). Kanamycine prevented the whole formation of the initiation complex by blocking the junction between the two ribosomal subunits [29]. The complete inhibition of this interaction was obtained with $1 \mathrm{mM}$ of kanamycin (Figure 4C).

These antibiotics acted with a different mechanism than ATA, since they bind different sites than oligonucleotides. Molar ratio values were also higher than with SD/ATG oligonucleotides alone, as well as $\Delta \mathrm{H}$, which were approximately $-2200 \mathrm{kcal} / \mathrm{mol}$ and -2500 $\mathrm{kcal} / \mathrm{mol}$ for tetracycline and kanamycine, respectively, as expected for a non-competitive inhibition.

\section{Discussion}

With these experiments, our purpose was not to test whether or not ssDNA could be used as a translational template in cells but rather to determine, with new approach, if general features of translation could be observed with ssDNA. All previous work had tested if ssDNA allowed direct translation, but results obtained were not really convincing and the possibility that only some steps could be restrictive was not checked. In order to gain access to global thermodynamics constants, we worked with a complex system of S30 extract, which has been largely used for in vitro translations as well as for binding experiments. Our results on RNA compared to ssDNA were very close to previous work which had been done on small oligonucleotides [9]. In this study, the relative behaviour of each template, RNA or ssDNA, was checked for some translation steps, but binding constants were not accessible. Access to the thermodynamic values allowed us to tackle new aspects of ssDNA translation. All 
interactions were characterized by the enthalpy-entropy compensation phenomenon; so the system paid a high entropic penalty for the bonding network to be formed. In our experiments, $\Delta \mathrm{S}$ was expressed in $\mathrm{kcal} / \mathrm{mole} . \mathrm{K}$ and not in cal $/ \mathrm{mole} . \mathrm{K}$ as usually encountered in biological binding interactions. These high entropic negative values, obtained for ssDNA as well as for RNA, indicate a strong organization in the system which probably corresponds to the initiation translational complex formation where many partners are involved. Moreover, the time interval between injections was longer that observed in more classical ITC experiments, since 200 to 300 seconds were required and slow thermal processes occurring upon injection were probably involved in reaching binding equilibrium.

Although the ribosome - polydT interaction was characterized by a high enthalpy, we presumed that this was due to non-specific hydrogen network formation. The ribosome does not have a defined binding site for the PolydT but a single strand nucleic molecule may present a large number of non-specific sites. By adding specific motifs, like ATG and SD sequences, to the ssDNA sequence, a decrease in the $\Delta \mathrm{H}$ was observed. We assumed that hybridization occurred and that the binding to the specific sites was favored. Being confronted with non-specific binding and uncertain reaction stoechiometry, we had to prove that hybridization occurred precisely between the different single-strand DNA and the 30S ribosome subunit. For this reason, we chose to monitor the binding in presence of antibiotics which specifically inhibited the translation initiation step.

The inhibition mechanisms of antibiotics are precisely known and largely described. For each of them the binding was fully reactive, and therefore functional. Aurintricarboxylic acid inhibited the attachment of mRNA to the 30S ribosome subunit, and tetracycline prevented the binding of tRNA on the 30S subunit. Kanamycine blocked the junction between the two ribosomal subunits. In each case, the whole initiation complex was blocked but the earlier the antibiotics acted, the lower the concentrations were necessary for a full effect. The results 
obtained perfectly matched this behaviour and demonstrated the specificity of the interactions measured. Moreover, the formation of a translational initiation complex was strongly driven by the ribosome, and if nucleic acids were the main actors involved in the specificity of this interaction, they played a second role in the affinity of this binding (see [30] for an excellent minireview). We then tested the binding between nucleic acid bearing the anti-SD sequence with the complementary SD sequence, which was the most important nucleic acid signal test in our system. As expected, this interaction contributed poorly to the affinity constant with a two order of magnitude difference.

These data strongly supported the binding constant validity obtained for ssDNA. From these results, it appeared that there was no difference between RNA and ssDNA in the binding step of initiation complex formation. Naturally, we tried to translate ssDNA, but as previously described elsewhere, direct DNA translation was not really efficient in absence of antibiotics such as neomycin $[5,6]$. It seemed that the elongation phase was the limiting step in the direct translation of single-stranded DNA. Whether direct participation of DNA in protein synthesis could play any role in vivo must be excluded, although such a role could be attractive for modelling the evolution of the earliest forms of life. 


\section{References}

[1] F. H. Crick, L. Barnett, S. Brenner, and R. J. Watts-Tobin, General nature of the genetic code for proteins, Nature 192 (1961) 1227-1232.

[2] F. Jacob, and J. Monod, Genetic regulatory mechanisms in the synthesis of proteins, J Mol Biol 3 (1961) 318-356.

[3] J. J. Holland, and B. J. McCarthy, Stimulation of Protein Synthesis in Vitro by Denatured DNA, Proc Natl Acad Sci U S A 52 (1964) 1554-1561.

[4] B. J. McCarthy, and J. J. Holland, Denatured DNA as a direct template for in vitro protein synthesis, Proc Natl Acad Sci U S A 54 (1965) 880-886.

[5] A. R. Morgan, R. D. Wells, and H. G. Khorana, Studies on polynucleotides. LXXIV.

Direct translation in vitro of single-stranded DNA-like polymers with repeating nucleotide sequences in the presence of neomycin B, J Mol Biol 26 (1967) 477-497.

[6] M. S. Bretscher, Direct translation of a circular messenger DNA, Nature 220 (1968) 10881091.

[7] M. S. Bretscher, Direct translation of bacteriophage fd DNA in the absence of neomycin B, J Mol Biol 42 (1969) 595-598.

[8] E. Jay, A. K. Seth, and G. Jay, Specific binding of a chemically synthesized prokaryotic ribosome recognition site. Prospect for molecular cloning and expression of eukaryotic genes, J Biol Chem 255 (1980) 3809-3812.

[9] R. D. Ricker, and A. Kaji, Use of single-stranded DNA oligonucleotides in programming ribosomes for translation, Nucleic Acids Res 19 (1991) 6573-6578.

[10] R. A. Calogero, C. L. Pon, M. A. Canonaco, and C. O. Gualerzi, Selection of the mRNA translation initiation region by Escherichia coli ribosomes, Proc Natl Acad Sci U S A 85 (1988) 6427-6431.

[11] M. Grunberg-Manago, and F. Gros, Initiation mechanisms of protein syntehesis, Prog Nucleic Acid Res Mol Biol 20 (1977) 209-284.

[12] J. Shine, and L. Dalgarno, The 3'-terminal sequence of Escherichia coli 16S ribosomal RNA: complementarity to nonsense triplets and ribosome binding sites, Proc Natl Acad Sci U S A 71 (1974) 1342-1346.

[13] M. N. Hall, J. Gabay, M. Debarbouille, and M. Schwartz, A role for mRNA secondary structure in the control of translation initiation, Nature 295 (1982) 616-618.

[14] A. C. Looman, J. Bodlaender, M. de Gruyter, A. Vogelaar, and P. H. van Knippenberg, Secondary structure as primary determinant of the efficiency of ribosomal binding sites in Escherichia coli, Nucleic Acids Res 14 (1986) 5481-5497.

[15] M. H. de Smit, and J. van Duin, Secondary structure of the ribosome binding site determines translational efficiency: a quantitative analysis, Proc Natl Acad Sci U S A 87 (1990) 7668-7672.

[16] S. Jones, D. T. Daley, N. M. Luscombe, H. M. Berman, and J. M. Thornton, ProteinRNA interactions: a structural analysis, Nucleic Acids Res 29 (2001) 943-954.

[17] B. T. Wimberly, D. E. Brodersen, W. M. Clemons, Jr., R. J. Morgan-Warren, A. P. Carter, C. Vonrhein, T. Hartsch, and V. Ramakrishnan, Structure of the 30S ribosomal subunit, Nature 407 (2000) 327-339.

[18] J. R. Williamson, Induced fit in RNA-protein recognition, Nat Struct Biol 7 (2000) 834837.

[19] G. Zubay, In vitro synthesis of protein in microbial systems, Annu Rev Genet 7 (1973) 267-287.

[20] J. M. Pratt, Coupled transcription-translation in prokaryotic cell-free systems, in Transcription and translation : A practical approach, Hames, B. D. \& Higgins, S. J., eds, IRL Press, New York (1984) 179-209. 
[21] J. F. Milligan, D. R. Groebe, G. W. Witherell, and O. C. Uhlenbeck, Oligoribonucleotide synthesis using T7 RNA polymerase and synthetic DNA templates, Nucleic Acids Res 15 (1987) 8783-8798.

[22] M. H. de Smit, and J. van Duin, Translational initiation on structured messengers. Another role for the Shine-Dalgarno interaction, J Mol Biol 235 (1994) 173-184.

[23] A. C. Looman, J. Bodlaender, L. J. Comstock, D. Eaton, P. Jhurani, H. A. de Boer, and P. H. van Knippenberg, Influence of the codon following the AUG initiation codon on the expression of a modified lacZ gene in Escherichia coli, Embo J 6 (1987) 2489-2492.

[24] J. Shine, and L. Dalgarno, Determinant of cistron specificity in bacterial ribosomes, Nature 254 (1975) 34-38.

[25] S. Ringquist, S. Shinedling, D. Barrick, L. Green, J. Binkley, G. D. Stormo, and L. Gold, Translation initiation in Escherichia coli: sequences within the ribosome-binding site, Mol Microbiol 6 (1992) 1219-1229.

[26] H. Chen, M. Bjerknes, R. Kumar, and E. Jay, Determination of the optimal aligned spacing between the Shine-Dalgarno sequence and the translation initiation codon of Escherichia coli mRNAs, Nucleic Acids Res 22 (1994) 4953-4957.

[27] A. P. Grollman, and M. L. Stewart, Inhibition of the attachment of messenger ribonucleic acid to ribosomes, Proc Natl Acad Sci U S A 61 (1968) 719-725.

[28] I. Chopra, and M. Roberts, Tetracycline antibiotics: mode of action, applications, molecular biology, and epidemiology of bacterial resistance, Microbiol Mol Biol Rev 65 (2001) 232-260 ; second page, table of contents.

[29] A. P. Carter, W. M. Clemons, D. E. Brodersen, R. J. Morgan-Warren, B. T. Wimberly, and V. Ramakrishnan, Functional insights from the structure of the $30 \mathrm{~S}$ ribosomal subunit and its interactions with antibiotics, Nature 407 (2000) 340-348.

[30] B. A. Maguire, and R. A. Zimmermann, The ribosome in focus, Cell 104 (2001) 813816. 

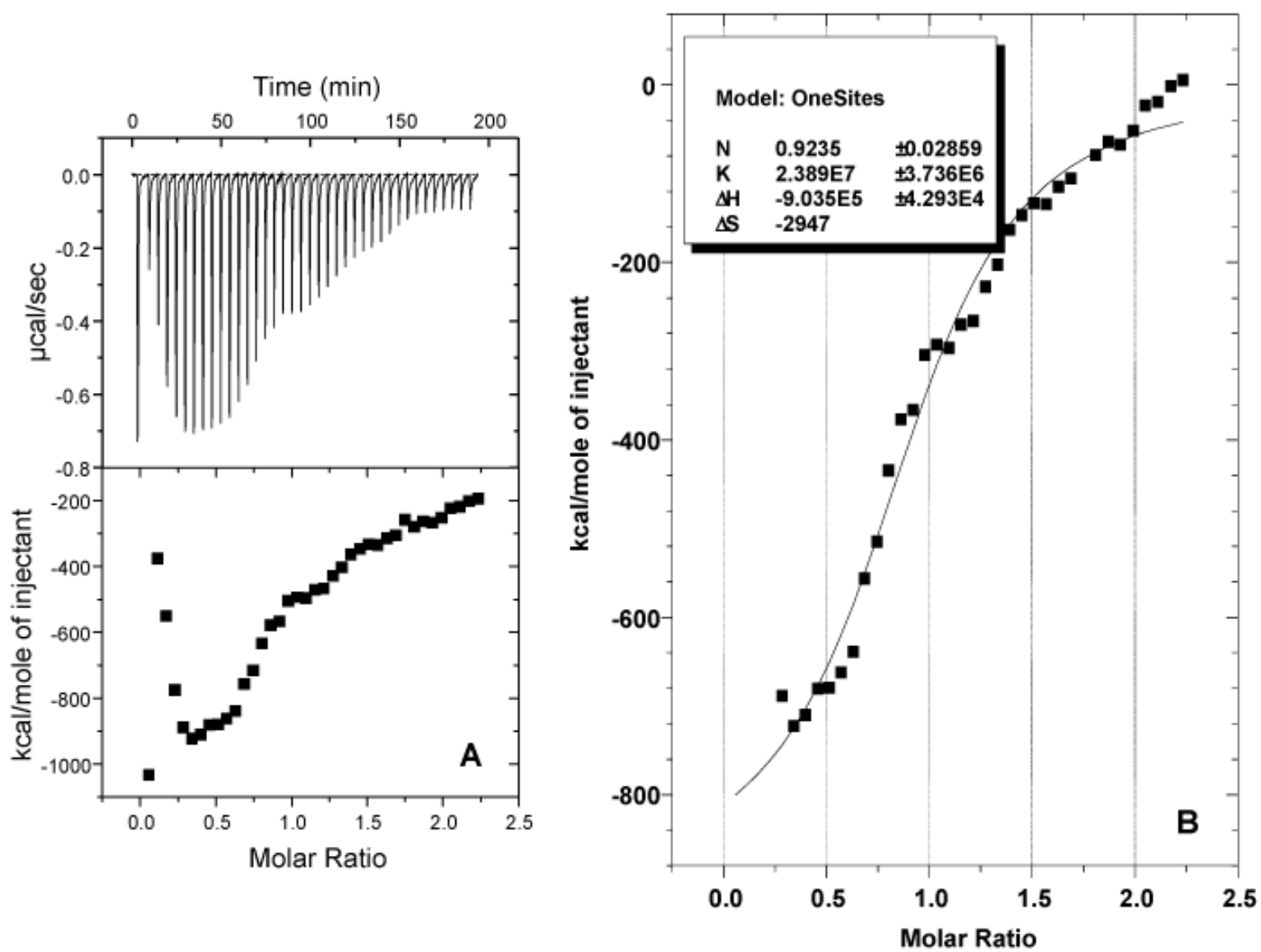

Figure 1 - ITC profile and binding isotherm of S30 extract and SD/ATG oligonucleotide interaction.

A: Top: raw datas obtained from 40 automatic injections ( $3 \mu 1$ each) with an interval of 300 sec by titration of SD/ATG $(10 \mu \mathrm{M})$ in $\mathrm{S} 30$ extract $(0.34 \mu \mathrm{M})$. Bottom: Integrated curve showing the experimental points. B: Integrated curve without the four first injections ( $\boldsymbol{\square})$ and giving the best fit (-). 


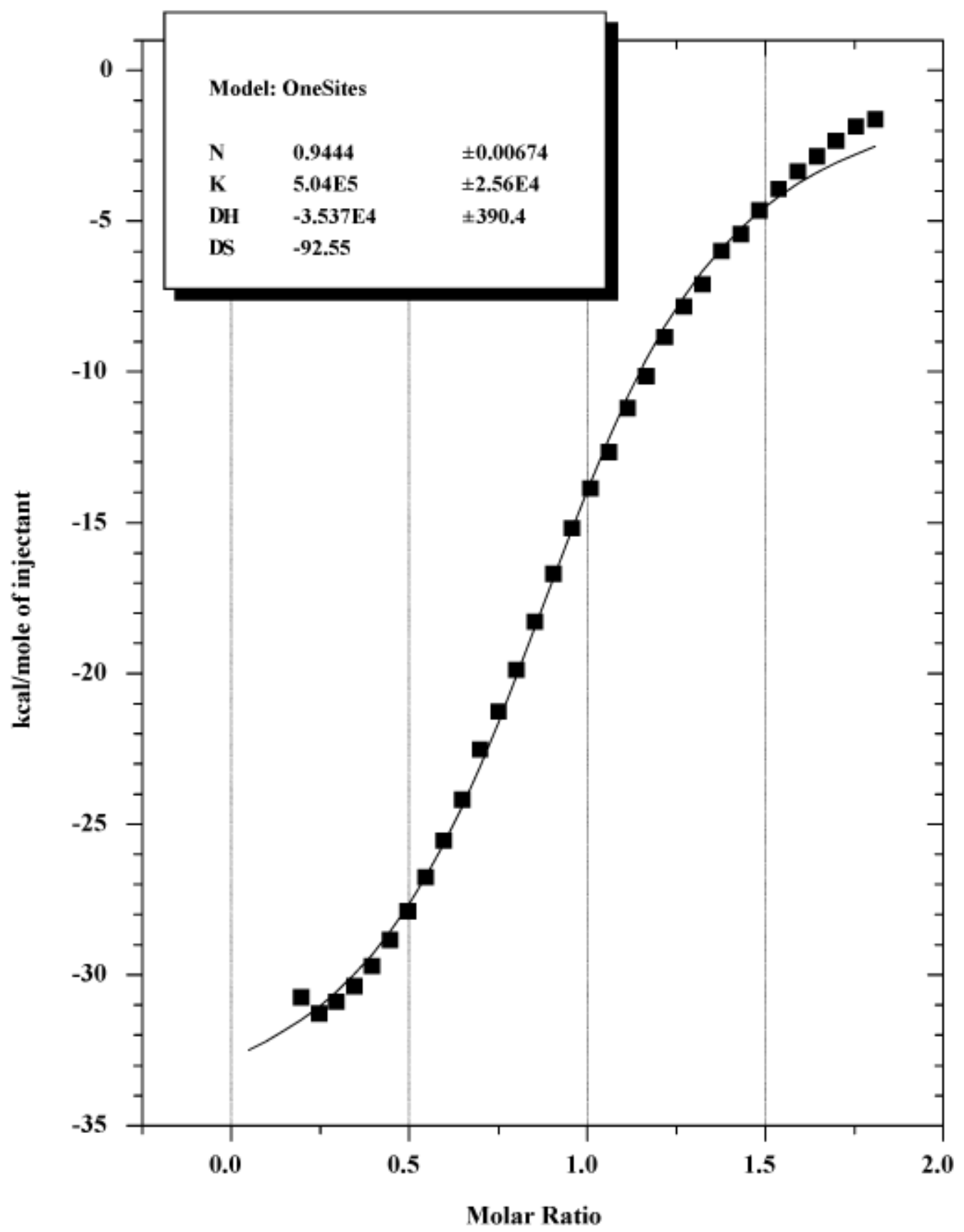

Figure 2 - Binding isotherm of anti-SD and SD/ATG oligonucleotides.

Integrated curve of interaction between anti-SD $(25 \mu \mathrm{M})$ and SD/ATG oligonucléotides

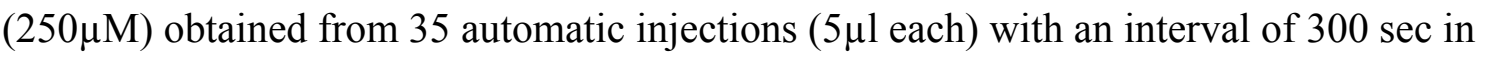
hybridization buffer $\left(50 \mathrm{mM} \mathrm{NaPO}_{4} \mathrm{pH} 7,100 \mathrm{mM} \mathrm{NaCl}\right)$. Experimental points $(\mathbf{\square})$ and best fit (一). 


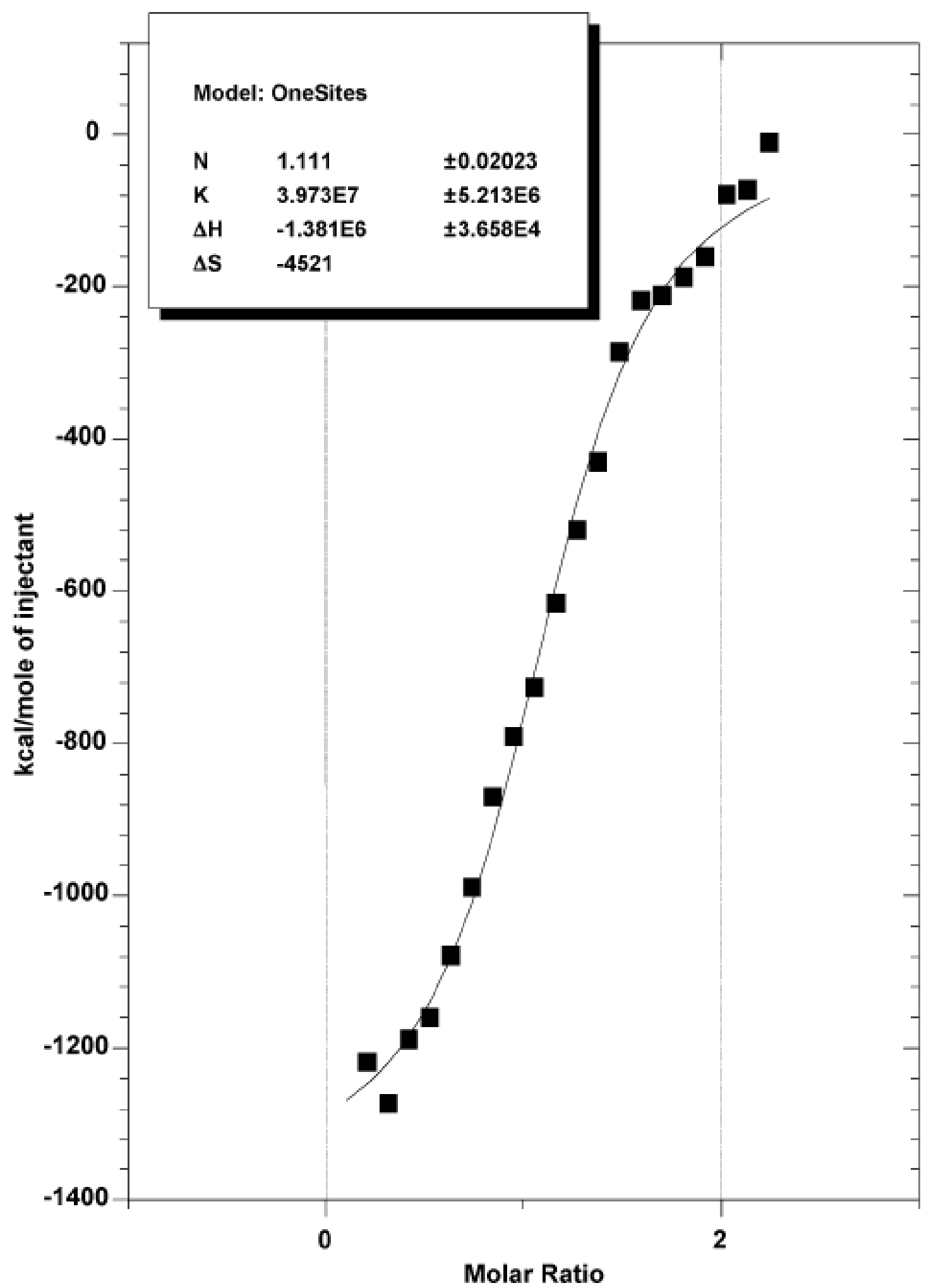

Figure 3 - Binding isotherm of S30 extract on RNA.

ITC treatment of S30 extract with $14 \mu \mathrm{M}$ of in vitro RNA transcript. Data were obtained from 21 automatic injections ( $3 \mu 1$ each) with an interval of 240 seconds between each. 

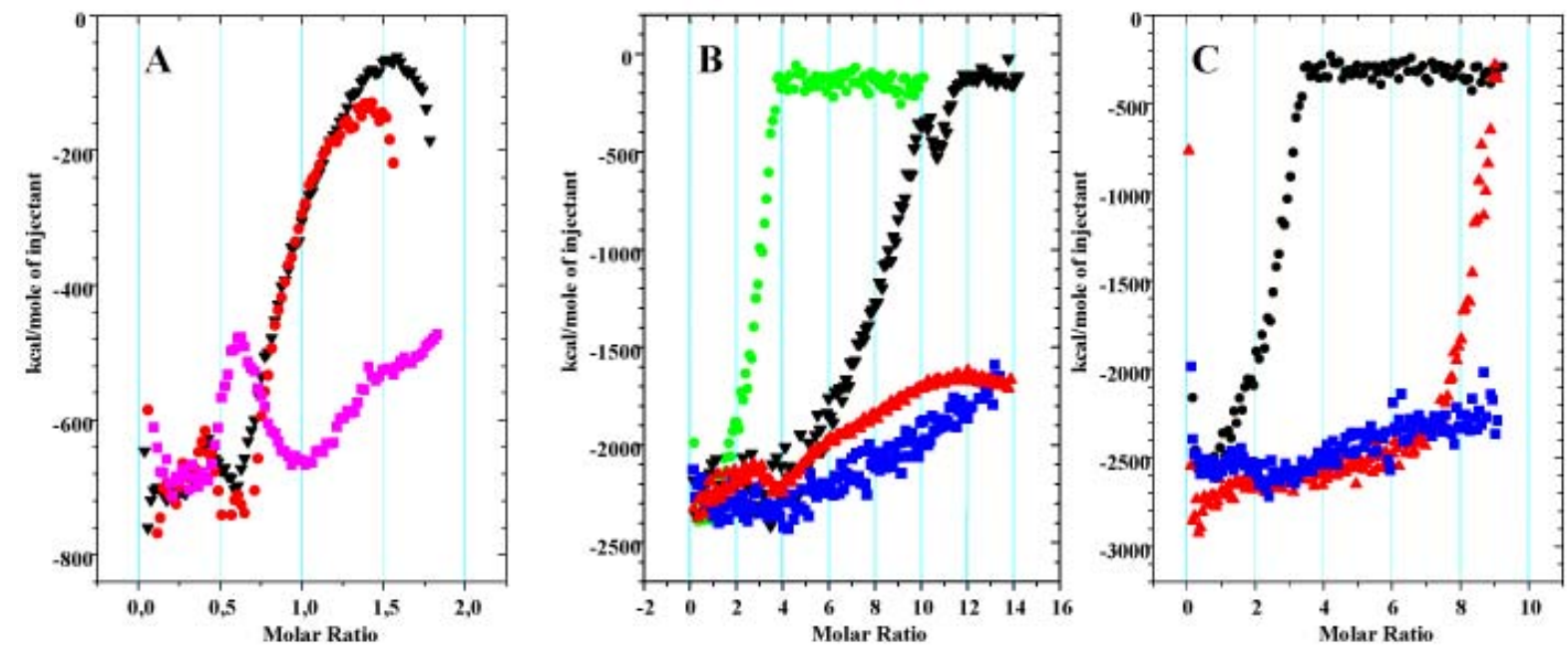

\section{Figure 4}

Effects of Aurintricarboxylic acid, Tetracycline and Kanamycine on binding with SD/ATG oligonucleotide.

A) Aurintricarboxylic acid. Integrated curve obtained with 90 automatic injections $(3 \mu 1$ each) with an interval of $200 \mathrm{sec}$. ATA: $(\nabla) 0 \mu \mathrm{M},(0) 1 \mu \mathrm{M}$ and ( $) 10 \mu \mathrm{M}$.

B) Tetracycline. Data were obtained from 148 automatic injections $(2 \mu l$ each) with an interval of 200 seconds. Tetracycline concentrations: $(\ominus) 0 \mu \mathrm{M}, \boldsymbol{\nabla}) 25 \mu \mathrm{M},(\boldsymbol{\Delta}) 100 \mu \mathrm{M},(\square) 250 \mu \mathrm{M}$.

C) Kanamycine. Data were obtained from 90 automatic injections $(2 \mu 1$ each) with an interval

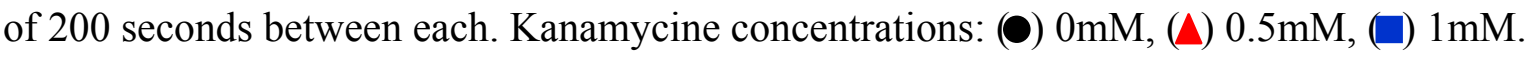

